\title{
Paediatric single mitochondrial DNA deletion disorders: an overlapping spectrum of disease
}

\author{
Alexander Broomfield • Mary G. Sweeney • Cathy E. Woodward • Carl Fratter • \\ Andrew M. Morris • James V. Leonard • Lara Abulhoul • Stephanie Grunewald • \\ Peter T. Clayton • Michael G. Hanna • Joanna Poulton • Shamima Rahman
}

Received: 27 July 2014 /Revised: 27 September 2014 / Accepted: 1 October 2014 / Published online: 29 October 2014

(C) The Author(s) 2014. This article is published with open access at Springerlink.com

\begin{abstract}
Background Single large-scale mitochondrial DNA (mtDNA) deletions (SLSMDs) are amongst the most frequently diagnosed mtDNA disorders in childhood, yet their natural history remains poorly understood. We report the natural history of a large multicentre cohort of such children.

Methods We reviewed case notes from three different UK centres to determine the clinical course of 34 patients (16 female, 18 male) with childhood-onset mitochondrial disease caused by SLSMDs. Kaplan-Meier analysis was used to compare survival of patients presenting with haematological features (Pearson syndrome) and those with nonhaematological presentations.
\end{abstract}

Communicated by: Eva Morava

Electronic supplementary material The online version of this article (doi:10.1007/s10545-014-9778-4) contains supplementary material, which is available to authorized users.

A. Broomfield · A. M. Morris

Genetic Medicine, Central Manchester University Hospitals NHS

Foundation trust, St Mary's Hospital, 6th Floor, Oxford Road,

Manchester M 13 9WL, UK

M. G. Sweeney • C. E. Woodward

Neurogenetics Unit, National Hospital for Neurology \&

Neurosurgery, Queen Square, London WC1N 3BG, UK

C. Fratter

Oxford Medical Genetics Laboratories, Oxford University Hospitals

NHS Trust, The Churchill Hospital, Oxford OX3 7LE, UK

J. V. Leonard

40A Bagley Wood Road, Kennington, Oxford OX1 5LY, UK

L. Abulhoul $\cdot$ S. Grunewald $\cdot$ S. Rahman

Metabolic Unit, Great Ormond Street Hospital NHS Foundation

Trust, Institute of Child Health, Great Ormond Street,

London WC1N 3JH, UK
Results The most frequent initial presentation was with isolated ptosis (16/34, $47 \%)$. Eleven (32\%) patients presented with transfusion-dependent anaemia soon after birth and were diagnosed with Pearson syndrome, whilst ten were classified as having Kearns-Sayre syndrome, three as having progressive external ophthalmoplegia (PEO) and seven as having PEO-plus. Three patients did not conform to any specific mitochondrial syndrome. The most frequently affected organ during the disease course was the kidney, with documented tubular or glomerular dysfunction in 17 of 20 (85\%) cases who had detailed investigations. SLSMDs were present in blood and/or urine cells in all cases tested, indicating that muscle biopsy is not necessary for diagnosis in the paediatric

S. Grunewald $\cdot$ P. T. Clayton $\cdot$ S. Rahman

Genetics and Genomic Medicine, UCL Institute of Child Health, 30 Guilford Street, London WC1N 1EH, UK

M. G. Hanna

MRC Centre for Neuromuscular Diseases, UCL Institute of

Neurology and National Hospital for Neurology and Neurosurgery, Queen Square, London WC1N 3BG, UK

J. Poulton

NDOG, Level 3, Women's Centre, John Radcliffe Hospital, Oxford, Oxfordshire OX3 9DU, UK

S. Rahman $(\bowtie)$

Mitochondrial Research Group, Genetics and Genomic Medicine, UCL Institute of Child Health, 30 Guilford Street, London WC1N $1 \mathrm{EH}, \mathrm{UK}$

e-mail: shamima.rahman@ucl.ac.uk 
age range. Kaplan-Meier survival analysis revealed significantly worse mortality in patients with Pearson syndrome compared with the rest of the cohort.

Conclusions Mitochondrial disease caused by SLSMDs is clinically heterogeneous, and not all cases conform to a classical mitochondrial syndrome. Multisystem disease is the norm, with anaemia, renal impairment and endocrine disturbance being the most frequent extraneurological features. SLSMDs should be considered in the differential diagnosis of all children presenting with ptosis.

\section{Background}

The overall incidence of mitochondrial disease is uncertain but has been estimated to be as frequent as 1 in 5,000 births (Skladal et al. 2003; Schaefer et al. 2004), with single, largescale mitochondrial DNA (mtDNA) deletions (SLSMDs) contributing to $10 \%$ of primary mtDNA disorders (Lamont et al. 1998). These deletions tend to occur spontaneously, possibly arising from defective mtDNA repair mechanisms (Krishnan et al. 2008) or defective mtDNA replication (Shoffner et al. 1989). In some cases, rearrangements are complex and many include duplicated mtDNA species (Poulton et al. 1993; Poulton et al. 1989).

The cornerstone of diagnosis has traditionally been the recognition of one of the classical phenotypes: Pearson marrow-pancreas syndrome, Kearns-Sayre syndrome (KSS), chronic progressive external ophthalmoplegia (CPEO or PEO) or (C)PEO-plus. Pearson syndrome was originally defined as a sideroblastic anaemia with associated exocrine pancreatic dysfunction (Pearson et al. 1979) but is now recognised as a multisystem mitochondrial disorder in which the chief feature is sideroblastic anaemia (Manea et al. 2009). KSS is defined as PEO with pigmentary retinopathy, presenting before the age of 20 years, with at least one of these additional findings: high cerebrospinal fluid (CSF) protein content, cardiac conduction block or ataxia (Rowland 1983). Isolated PEO is considered a more benign single-system disorder affecting skeletal muscle and is characterised by ptosis, ophthalmoplegia and variably severe proximal limb weakness (Biousse and Newman 2001). The term CPEO-plus was coined by Drachman in 1968 (Drachman 1968) and is now used to describe patients with PEO who, whilst not fulfilling the criteria for KSS, have multisystem involvement (Di Mauro and Hirano 1993). While these clinical phenotypes have been the mainstay of recognition of SLSMD disorders, increasing experience has begun to demonstrate considerable overlap between these syndromes (Pitceathly et al. 2012, Manea et al. 2009; Yamashita et al. 2008; Grady et al. 2014).

We report a large multicentre paediatric-onset cohort that demonstrates the clinical overlap of SLSMD disorders presenting in childhood and adds weight to the view that the apparently distinct Pearson and Kearns-Sayre syndromes form part of a continuous spectrum of disease (Dimauro 2007; Lopez-Gallardo et al. 2009). Moreover, the findings reported in our study emphasise the importance of investigating apparently isolated ptosis presenting in childhood and of a detailed renal evaluation in all patients with SLSMDs.

\section{Patients and methods}

We conducted a multicenter case-notes review of childhoodonset SLSMDs diagnosed between 1988 and 2011. All patients diagnosed with symptom onset before age 16 years were identified through the National Health Service (NHS) Highly Specialised Services-funded mitochondrial molecular diagnostic laboratories at the National Hospital for Neurology, London, and the Oxford Radcliffe Hospitals, Oxford. Molecular diagnosis of SLSMD was achieved in all cases by Southern blot and/or long-range polymerase chain reaction (PCR) of DNA extracted from peripheral blood leukocytes, urinary epithelial cells or skeletal muscle. All genetic studies were performed after informed consent from parents/legal guardians of the patients. Identification of the deletion break point was performed by Sanger sequencing with the use of appropriate primers where samples were available. Quantitation of mitochondrial deletion mutation load compared with the wild type was determined visually by experienced scientists. This visual method of quantitation on autoradiographs has been validated over a number of years by the blinded visual comparison of deletion load with that found using densitometry (Holt et al. 1989; McShane et al. 1991), and we previously established that this is associated with an operator error of $5 \%$ compared with densitometry reading (unpublished observations).

$\mathrm{AB}$ or SR reviewed all case notes, and clinical data (including symptom onset, multisystem disease features, neuroimaging, muscle histology and histochemistry, blood and CSF biochemistry, respiratory-chain enzyme activities in muscle, genetic data) were collated using a structured pro forma. Statistical analysis was performed using the SPSS 16 (SPSS for Windows, Version 16.0. Chicago, IL, USA). The Bonferroni correction was used for multivariate regression analysis, and KaplanMeier analysis was performed for comparison of survival outcomes. Statistical significance was set at $p<0.05$. Ethical approval for the study was obtained from the National Research Ethics Committee London, Bloomsbury, UK.

\section{Results}

Demographics

Thirty-four patients were identified: 16 female and 18 male. There was no family history in any case except one set of 
identical twins, patients $\mathrm{P}$ and $\mathrm{Q}$, who presented very similar clinical features (Table 1). Eleven patients were diagnosed with Pearson syndrome, ten with KSS, three with PEO and seven with PEO-plus. However, three patients (K, L and R) did not correspond to any of these classical phenotypes (Table 2). The details of their initial presentation are shown in Table 1.
Initial presentation

The initial symptoms at presentation are illustrated in Fig. 1. In $42 \%$ of patients (16 of 34 ), the first symptom was ptosis, while haematological manifestations associated with Pearson syndrome were the second most frequent presenting feature,

Table 1 Demographics and clinical features at presentation

\begin{tabular}{|c|c|c|c|c|c|c|c|}
\hline Patient & Sex & Onset & Age at diagnosis & Age at death & $\begin{array}{l}\text { Age at last } \\
\text { review (years) }\end{array}$ & $\begin{array}{l}\text { Birth weight } \\
(\mathrm{kg})\end{array}$ & Presenting complaint \\
\hline A & $\mathrm{F}$ & Birth & 1.5 months & 5 years 3 months & & 2.5 & Anaemia at birth \\
\hline B & M & Birth & 2 years 2 months & 7 years 5 months & & 3.46 & Poor feeding, then anaemia \\
\hline $\mathrm{C}$ & M & Birth & 7 years 10 months & & 8.5 & 3.4 & Anaemia at birth \\
\hline $\mathrm{D}$ & $\mathrm{F}$ & Birth & 5 months & 2 years 6 months & & $\begin{array}{l}1.6 \text { (Twin } 2,34 \\
\text { weeks' gestation) }\end{array}$ & Anaemia at birth \\
\hline $\mathrm{E}$ & $\mathrm{F}$ & Birth & 1 months & 4 months & & 1.54 & IUGR/pancytopenia/diabetes mellitus/RVH \\
\hline $\mathrm{F}$ & M & Birth & 4 years 8 months & & 6 & 3.35 & Ptosis + anaemia \\
\hline G & $\mathrm{F}$ & Birth & 2 months & 14 months & & $\begin{array}{l}1.7 \text { (Twin } 1,34 \\
\text { weeks' gestation) }\end{array}$ & Anaemia \\
\hline $\mathrm{H}$ & M & 2 months & 13 months & 2 years 4 months & & 3.7 & Intermittent dyspnoea + anaemia \\
\hline I & $\mathrm{F}$ & 5 months & 2 years 8 months & 4 years 5 months & & 3 & Anaemia \\
\hline $\mathrm{J}$ & M & 16 months & 2 years & & 6 & NA & Anaemia \\
\hline $\mathrm{K}$ & $\mathrm{F}$ & 6 months & 21 months & 16 years 2 months & & 3.9 & Failure to thrive + diarrhoea \\
\hline $\mathrm{L}$ & M & 2 years & 14 years & & 24 & NA & Fanconi syndrome + rickets \\
\hline M & M & 2 years & 6 years & 11 years $5 \mathrm{~m}$ & & 2.9 & Left-sided ptosis \\
\hline $\mathrm{N}$ & $\mathrm{F}$ & $\begin{array}{l}2 \text { years } \\
6 \text { months }\end{array}$ & 6 years & & 10 & NA & Ptosis \\
\hline $\mathrm{O}$ & M & 3 years & 6 years & 21 years & & 3.8 & Low appetite/low energy/hyponatraemia \\
\hline $\mathrm{P}$ & M & 4 years & 8 years & & 12 & 1.7 (Twin 2) & $\begin{array}{l}\text { Ptosis at } 4 \text { years, adrenal insufficiency } \\
\text { at } 5 \text { years }\end{array}$ \\
\hline Q & M & 5 years & 8 years & & 12 & $2.8($ Twin 1$)$ & $\begin{array}{l}\text { Adrenal insufficiency investigated after } \\
\text { twin 2's diagnosis }\end{array}$ \\
\hline $\mathrm{R}$ & M & Birth & 3 months & 1 year 9 months & & 2.32 & $\begin{array}{l}\text { Poor feeding, hypoglycaemia, faltering } \\
\text { growth, lactic acidosis }\end{array}$ \\
\hline $\mathrm{S}$ & $\mathrm{F}$ & 12 years & 17 years & & 25 & 3.05 & Ptosis onset at 12 years \\
\hline $\mathrm{T}$ & $\mathrm{F}$ & 8 years & 12 years & & 12 & NA & $\begin{array}{l}\text { Tremor }+ \text { migraine at } 8 \text { years, ptosis at } \\
12 \text { years }\end{array}$ \\
\hline $\mathrm{U}$ & $\mathrm{F}$ & 5 years & 19 years & & 19 & NA & Ptosis \\
\hline $\mathrm{V}$ & $\mathrm{F}$ & 7 years & 8 years & & 20 & NA & Ptosis \\
\hline $\mathrm{W}$ & M & 5 years & 10 years & & 15 & NA & Recurrent inflammation of the eye \\
\hline $\mathrm{X}$ & $\mathrm{F}$ & 15 years & 25 years & & 25 & NA & Ptosis from early childhood \\
\hline $\mathrm{Y}$ & M & 14 years & 24 years & & 24 & NA & Ptosis \\
\hline Z & M & 8 years & 13 years & & 13 & 2.2 & Ptosis \\
\hline AA & M & 11 years & 13 years & & 13 & 3.06 & Ptosis \\
\hline $\mathrm{AB}$ & $\mathrm{F}$ & 5 years & 9 years & & 15 & NA & Ptosis \\
\hline $\mathrm{AC}$ & M & 6 years & 13 years & & 17 & 3.85 & Ptosis \\
\hline $\mathrm{AD}$ & $\mathrm{F}$ & 7 years & 12 years & & 22 & NA & Ptosis \\
\hline $\mathrm{AE}$ & $\mathrm{F}$ & 7 years & 18 years & & 25 & NA & Ptosis, then muscular weakness at 14 years \\
\hline $\mathrm{AF}$ & M & 5 years & 8 years & & 13 & 2.5 & Short stature, poor appetite \\
\hline AG & M & 4 months & 5 months & & 2.5 & 3.96 & Anaemia and failure to thrive \\
\hline $\mathrm{AH}$ & $\mathrm{F}$ & $\begin{array}{l}9 \text { years } \\
6 \text { months }\end{array}$ & 11 years & & 15 & 2.28 & Ptosis \\
\hline
\end{tabular}

IUGR intrauterine growth restriction, $R V H$ right ventricular hypertrophy, $N A$ not available 
Table 2 Genotypic data

\begin{tabular}{|c|c|c|c|c|c|c|}
\hline Patient & Clinical diagnosis & Tissue investigated & Deletion breakage points (bp) & Size $(k b)$ & Number of tRNA genes deleted & $\%$ heteroplasmy \\
\hline A & Pearson & Bone marrow & Common del $(8473 \rightarrow 13447)$ & 4.97 & 5 & 80 \\
\hline B & Pearson & Muscle & $12102 \rightarrow 14113$ & 2.01 & 3 & 85 \\
\hline $\mathrm{C}$ & Pearson & Muscle & Common del $(8473 \rightarrow 13447)$ & 4.97 & 5 & 90 \\
\hline $\mathrm{D}$ & Pearson & Blood & NA & $5^{\mathrm{a}}$ & NA & NA \\
\hline $\mathrm{E}$ & Pearson & Muscle & Common del $(8473 \rightarrow 13477)$ & 4.97 & 5 & 90 \\
\hline $\mathrm{F}$ & Pearson & Blood & $7983 \rightarrow 13983$ & 6 & 6 & 86 \\
\hline G & Pearson & Blood & Common del $(8474 \rightarrow 13447)$ & 4.97 & 5 & 70 \\
\hline $\mathrm{H}$ & Pearson & Blood & NA & $2.7^{\mathrm{a}}$ & NA & 70 \\
\hline I & Pearson & Blood & Common del $(8473 \rightarrow 13446)$ & 4.97 & 5 & 70 \\
\hline $\mathrm{J}$ & Pearson & Blood & NA & $>5^{\mathrm{a}}$ & NA & 50 \\
\hline $\mathrm{K}$ & Unclassified & Blood & NA & $5.5^{\mathrm{a}}$ & NA & 50 \\
\hline $\mathrm{L}$ & Unclassified & Blood & NA & $4.2^{\mathrm{a}}$ & NA & NA \\
\hline M & KSS & Blood & NA & $7^{\mathrm{a}}$ & NA & NA \\
\hline $\mathrm{N}$ & KSS & $\begin{array}{l}\text { Blood } \\
\text { Urine }\end{array}$ & $7909 \rightarrow 13378$ & 5.46 & 6 & $\begin{array}{l}70 \\
85\end{array}$ \\
\hline $\mathrm{O}$ & KSS & Blood & NA & $3.9^{\mathrm{a}}$ & NA & \\
\hline $\mathrm{P}$ & $\mathrm{PEO}+$ & Blood & $7771 \rightarrow 15406$ & 7.6 & 7 & 60 \\
\hline Q & $\mathrm{PEO}+$ & Blood & $7771 \rightarrow 15406$ & 7.6 & 7 & 60 \\
\hline $\mathrm{R}$ & Unclassified & Blood & Common del $(8467 \rightarrow 13447)$ & 4.96 & 5 & 85 \\
\hline S & KSS & Muscle & Common del $(8473 \rightarrow 13447)$ & 4.97 & 5 & 80 \\
\hline $\mathrm{T}$ & KSS & Blood & Common del $(8482 \rightarrow 13477)$ & 4.97 & 5 & NA \\
\hline $\mathrm{U}$ & PEO & Muscle & Common del $((8473 \rightarrow 13477)$ & 4.97 & 5 & 45 \\
\hline $\mathrm{V}$ & KSS & $\begin{array}{l}\text { Blood } \\
\text { Muscle }\end{array}$ & Common del $(8473 \rightarrow 13477)$ & 4.97 & 5 & $\begin{array}{l}55 \\
45\end{array}$ \\
\hline W & KSS & Blood & Common del $(8473 \rightarrow 13477)$ & 4.97 & 5 & 50 \\
\hline $\mathrm{X}$ & PEO & Muscle & Common del $(8473 \rightarrow 13477)$ & 4.97 & 5 & 60 \\
\hline $\mathrm{Y}$ & $\mathrm{PEO}+$ & Muscle & Common del $(8483 \rightarrow 13477)$ & 4.97 & 5 & 60 \\
\hline Z & KSS & Urine & Common del $(8474 \rightarrow 13477)$ & 4.97 & 5 & 50 \\
\hline AA & $\mathrm{PEO}+$ & Blood & NA & $5^{\mathrm{a}}$ & NA & NA \\
\hline $\mathrm{AB}$ & $\mathrm{PEO}+$ & Blood & NA & $3.6^{\mathrm{a}}$ & NA & NA \\
\hline $\mathrm{AC}$ & KSS & Blood & NA & $7.5^{\mathrm{a}}$ & NA & 45 \\
\hline $\mathrm{AD}$ & PEO & Muscle & NA & $4.4^{\mathrm{a}}$ & NA & 75 \\
\hline $\mathrm{AE}$ & $\mathrm{PEO}+$ & Muscle & Common del $(8473 \rightarrow 13477)$ & 4.97 & 5 & NA \\
\hline $\mathrm{AF}$ & KSS & Muscle & $6133 \rightarrow 14092$ & 7.96 & 11 & 55 \\
\hline AG & Pearson & Blood & Common del $(8473 \rightarrow 13477)$ & 5 & 5 & 80 \\
\hline $\mathrm{AH}$ & $\mathrm{PEO}+$ & Blood & NA & $5.1^{\mathrm{a}}$ & NA & 25 \\
\hline
\end{tabular}

del deletion, KSS Kearns-Sayre syndrome, $P E O$ progressive external ophthalmoplegia, $P E O+$ PEO with additional clinical features, $N A$ not available ${ }^{a}$ Approximate size

occurring in $32 \%$ (11 of 34). Median age at presentation was 1 week [interquartile range (IQR) 3 months] for these 11 patients, and 6 years (IQR 5 years) for those not diagnosed with Pearson syndrome.

Survival

Overall, 11 patients died: seven with Pearson syndrome, two with KSS and two with atypical presentations. Kaplan-Meier survival analysis (Fig. 2) revealed a significant difference $(p=0.01)$ in mortality between those with Pearson syndrome when compared with the other clinical phenotypes. Survival at 18 years was $22 \%$ for Pearson syndrome and $73 \%$ for patients with other clinical presentations.

Haematological involvement

Table S1 details the haematological manifestations observed in the 11 patients diagnosed with Pearson syndrome. Most of these cases presented soon after birth with transfusion- 


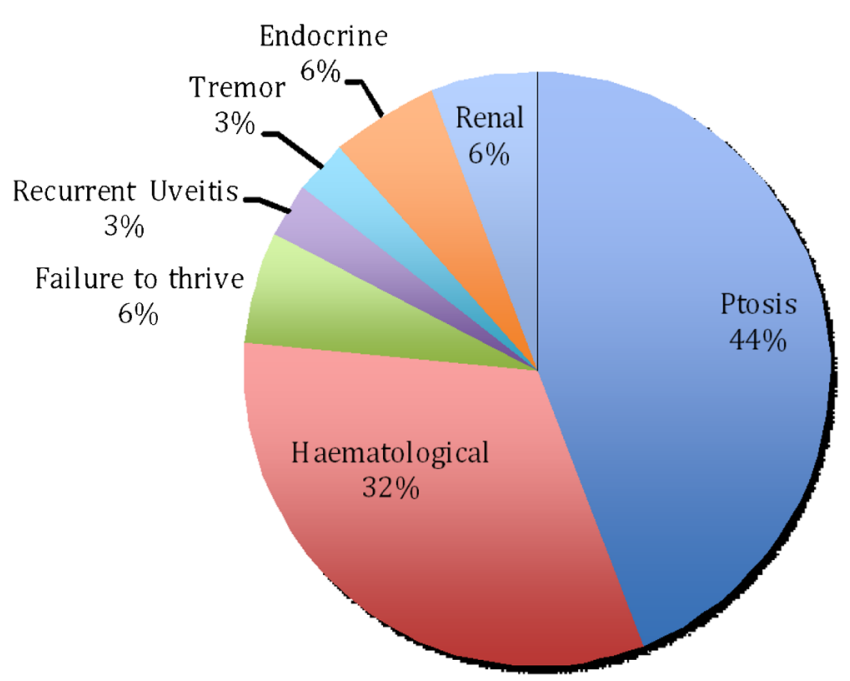

Fig. 1 Clinical features at presentation. Initial clinical problems in 34 patients with childhood-onset mitochondrial disease caused by single large-scale mitochondrial DNA deletions

dependent anaemia. Neutropaenia developed in ten patients, and thrombocytopaenia was documented in eight cases. Bone marrow aspirates were performed in ten patients; all had vacuolization of haematopoietic precursors, although classical ringed sideroblasts were observed in only seven cases. No evidence of impaired haematopoeisis was documented in the other 23 patients.

Gastrointestinal and endocrine involvement and growth

Birth weight was $<3$ rd centile in six of 22 patients whose birth weights were available. It is to be noted that two of these six patients, D and G, were both born prematurely at 34 weeks; two patients, $\mathrm{B}$ and $\mathrm{F}$, were second babies of twin pregnancies. The weight of 19 of 30 patients, for whom serial auxology was available, fell below the 3rd centile during follow-up (Table S2).

Four patients with Pearson syndrome had a history of recurrent diarrhoea, three of whom had reduced faecal elastase suggesting pancreatic insufficiency (Table S2). Overall, five of 16 patients tested had reduced faecal elastase, four of whom fulfilled criteria for classical Pearson syndrome. However, patient $\mathrm{K}$ never had any haematological problems (Morris et al. 1997). Patient $K$ also developed a severe enteropathy with marked inflammatory cell infiltrate at age 4 years, necessitating parenteral nutrition for 6 months. Patient $\mathrm{M}$ developed severe abdominal pain, nausea, vomiting and diarrhoea at 10 years and had documented gastroparesis on electrogastrography and gastric-emptying scintigraphy studies. Of note, patient $\mathrm{E}$, who had diabetes mellitus but no symptoms suggestive of malabsorption, had a hypoplastic pancreas on autopsy.

Endocrine dysfunction was a frequent occurrence: three patients $(\mathrm{P}, \mathrm{Q}$ and $\mathrm{W})$ had cortisol deficiency requiring steroid supplementation, one (A) had hypothyroidism, three (J, W, V) had hypoparathyroidism and nine had glucose tolerance tests indicative of diabetes mellitus. Of these nine, two patients (A and G) had concurrent pancreatic exocrine insufficiency suggesting global pancreatic dysfunction. Patients $\mathrm{M}, \mathrm{W}$ and $\mathrm{AF}$ were shown to have growth hormone insufficiency and had a good clinical response to growth hormone supplementation.

\section{Renal disease}

Impairment of renal function defined as either a reduction of glomerular filtration rate (GFR), measured by isotope excretion, or an abnormal elevation of urinary tubulopathy markers retinol binding protein (RBP) (Bernard et al. 1987) or Nacetyl-3-glucosaminidase (NAG) (Vaidya et al. 2008), i.e. an abnormal RBP/creatinine and/or an abnormal NAG/creatinine ratio, was observed in 14 of 20 patients in whom renal function had been investigated in detail (Table S3). Five of eight patients tested had abnormal GFRs, four of whom (A, K, L and $\mathrm{W}$ ) also showed elevation of urinary tubulopathy markers suggesting global impairment of both filtration and tubular function. Patient $\mathrm{K}$ developed end-stage renal failure. Of the 16 patients who had NAG and RBP/creatinine ratios examined, both were elevated in 13, NAG in two and one was normal for both. In addition to the 20 patients who had formal investigations, two ( $\mathrm{G}$ and $\mathrm{H})$ were deemed likely to have had a tubulopathy given their combination of aminoaciduria and
Fig. 2 Kaplan-Meier survival graph showing overall survival to 18 years of 34 patients with single large-scale mitochondrial DNA deletions, compared with subgroups with a diagnosis of Pearson syndrome $(n=11)$ and those without haematological involvement. $(p<0.001$ MantelCox log-rank test.)

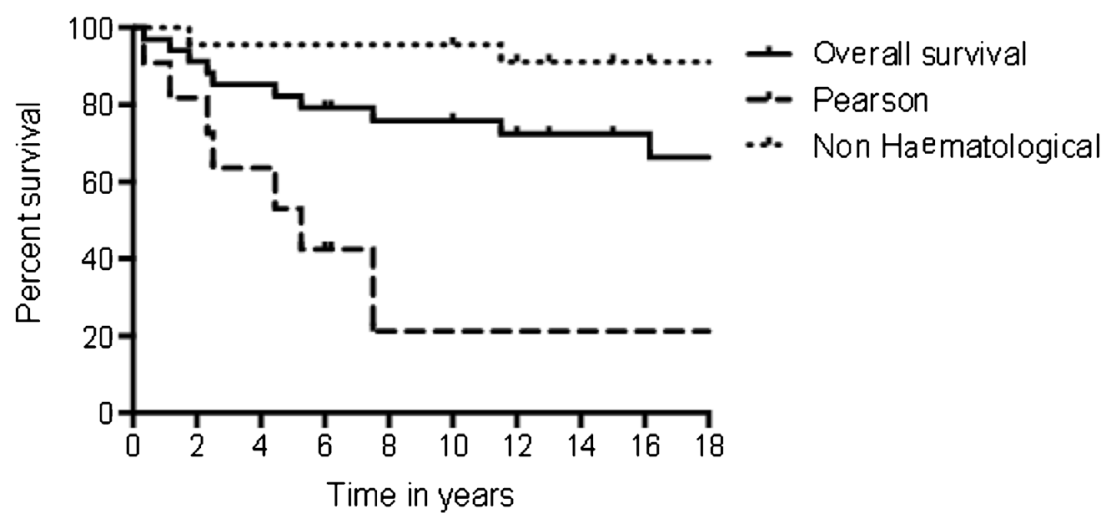


polyuria; however, this was never formally investigated. Four of seven renal biopsies were normal histologically despite severely reduced GFRs in three of these cases, while two biopsies revealed calcium deposition and the seventh showed cystic dilatation.

\section{Cardiac function}

Cardiac function was assessed using electrocardiogram (ECG) (29 patients) and echocardiogram (28 patients), and abnormalities were detected in 13 . Rhythm disturbances were found in nine of the 29 patients examined, including complete heart block in five (A, N, O, V and AF) at 5, 9, 12, 13 and 8 years, respectively. Patient A had a heart rate of only 20 beats per minute prior to pacing and died 3 weeks after developing complete heart block (Rahman et al. 2000). Patient N, alive 26 months after insertion of pacemaker, has severe cardiomyopathy with inter- and intraventricular dyssynchrony, dyskinetic ventricular septum and fractional shortening of $18 \%$ despite high-dose lisinopril therapy. Two patients (I and $\mathrm{W}$ ) developed incomplete right bundle branch block, a known precursor to more severe pathogenic conduction defects (Riera et al. 2008), having previously had normal ECGs. Other abnormalities noted included supraventricular disturbances ( $\mathrm{Y}$ and $\mathrm{L}$ ), first-degree block ( $\mathrm{Z}$ ), left ventricular hypertrophy $(\mathrm{LVH})(\mathrm{K}$ and $\mathrm{R})$ and right ventricular hypertrophy $(\mathrm{RVH})(\mathrm{H})$.

\section{Neurological features and neuroimaging}

The most frequent neurological manifestation was ptosis, affecting 22 patients, although only nine had frank external ophthalmoplegia (Table 3). Interestingly, all of those who presented with ptosis, except patients $\mathrm{W}$ and $\mathrm{Y}$, were given an initial diagnosis of congenital ptosis despite only patient $\mathrm{F}$ being symptomatic before the age of 1 year. Retinal dystrophy was observed in 13 patients, while patients $\mathrm{B}, \mathrm{L}$ and $\mathrm{W}$ had corneal thickening, a previously unrecognised manifestation of SLSMD diseases. A delay in achievement of gross motor milestones was seen in nine of 34 patients, while 18 had clinical signs of neurological involvement, including eight with hypotonia, nine with reduced power and two with ataxia. Only three patients were reported to have seizures (Table 3).

Ten of 15 patients tested had sensorineural hearing loss, including patient $\mathrm{K}$ who required cochlear implants (Table 3). Brain magnetic resonance imaging (MRI) was abnormal in nine (J, K,M, N, Q, R, T, W and AF) of 13 patients examined (Table 3). In eight cases, the predominant finding was of basal ganglia changes, but six also had white matter changes, whilst patient $\mathrm{R}$ had changes suggestive of a neuronal migration defect. Neuroimaging in the four patients (J, M, N and Z) with low levels of CSF 5-methyltetrahydrofolate (5-MTHF) revealed white matter lesions in the three severely affected, but patient $\mathrm{Z}$, whose level was only just below the normal range, had a normal scan.

\section{Muscle histology and histochemistry}

Muscle biopsies were performed in 14 patients and were abnormal in 12 cases (Table 3). Ragged red fibres were observed in all 12 abnormal biopsies, whilst cytochrome oxidase (COX)-negative fibres were seen in 11. Excessive lipid was observed in seven, while abnormalities in mitochondrial morphology on electron microscopy were seen in six. The two other histologically normal biopsies were both small samples and in the case of patient $\mathrm{K}$ was performed at the relatively early age of 9 months, while electron microscopy was not performed in patient $\mathrm{H}$.

\section{Biochemistry}

Blood lactate was raised $(>2.0 \mathrm{mmol} / \mathrm{l})$ in the majority ( 21 of $30,70 \%$ ) of patients tested (Table S4). Of the 20 who had concurrent amino acid profiles performed, $15 \mathrm{had}$ an accompanying rise in plasma alanine to $492-889 \mu \mathrm{mol} / \mathrm{L}$ (reference $<450 \mu \mathrm{mol} / \mathrm{l}$ ). Plasma alanine was elevated in 15 patients, but patients $\mathrm{M}, \mathrm{Q}$ and $\mathrm{W}$ had no accompanying rise in lactate. Raised levels of lactate were noted in the urine of all patients except W. Patient $\mathrm{M}$ also had a raised plasma proline at $323 \mu \mathrm{mol} / \mathrm{L}$ (reference $85-290 \mu \mathrm{mol} / \mathrm{l}$ ). Urinary organic acid analysis revealed an increase in 3-hydroxybutyrate in ten of 17 patients tested, suggestive of a shift in cellular redox potential to a more reduced state. Two patients (B and R) had raised levels of tricarboxylic acid cycle metabolites. CSF lactate was elevated $(>1.8 \mathrm{mmol} / \mathrm{L})$ in all ten patients tested. CSF protein was markedly elevated in all nine patients for whom data was available, in keeping with a diagnosis of KSS, although one of these (R) did not fulfil diagnostic criteria for KSS, since there was no ophthalmoplegia. All four patients who had CSF 5MTHF determined had low levels, although two cases ( $\mathrm{J}$ and Z) had initial normal values but later had undetectable levels (at the ages of 6 and 15 years, respectively).

\section{Genetics}

Of the 34 patients in this cohort, the diagnosis of SLSMDs was established in 22 by analysis of blood DNA. Of the other 12 , muscle was analysed in ten and urinary epithelial cells and tissue obtained from a bone marrow aspirate in one case each (Table 2). Breakage points were determined for 22 patients: 12 in blood, eight in muscle and one each in tissue from a bone marrow aspirate and urinary tract epithelial cells. Of these 22,16 had the common $4.97 \mathrm{~kb}$ mtDNA deletion. There was no correlation between age of presentation and size of deletion in these 22 patients, but there was a statistically significant but weak correlation between per cent of deletion found in tissue and age at 


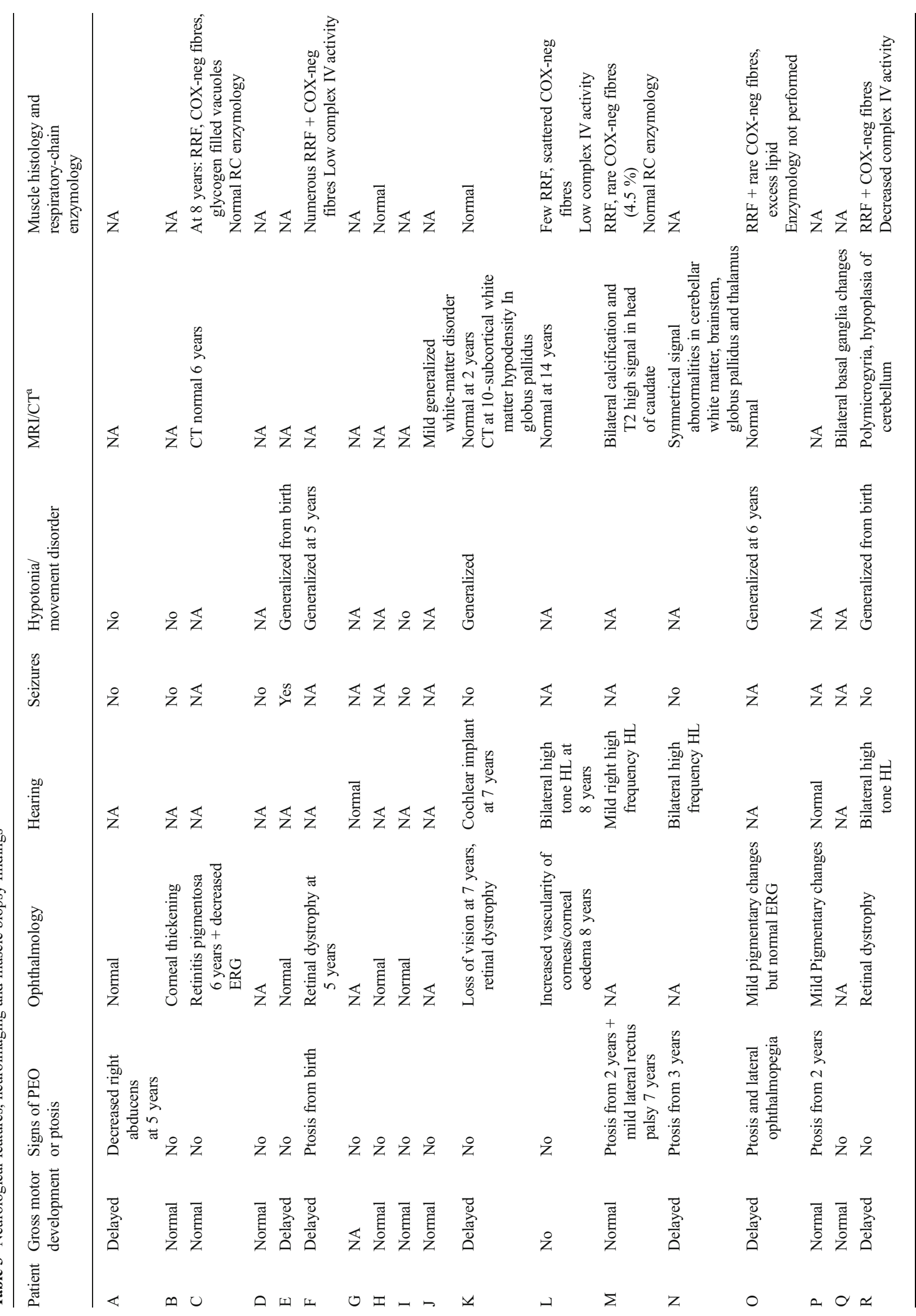




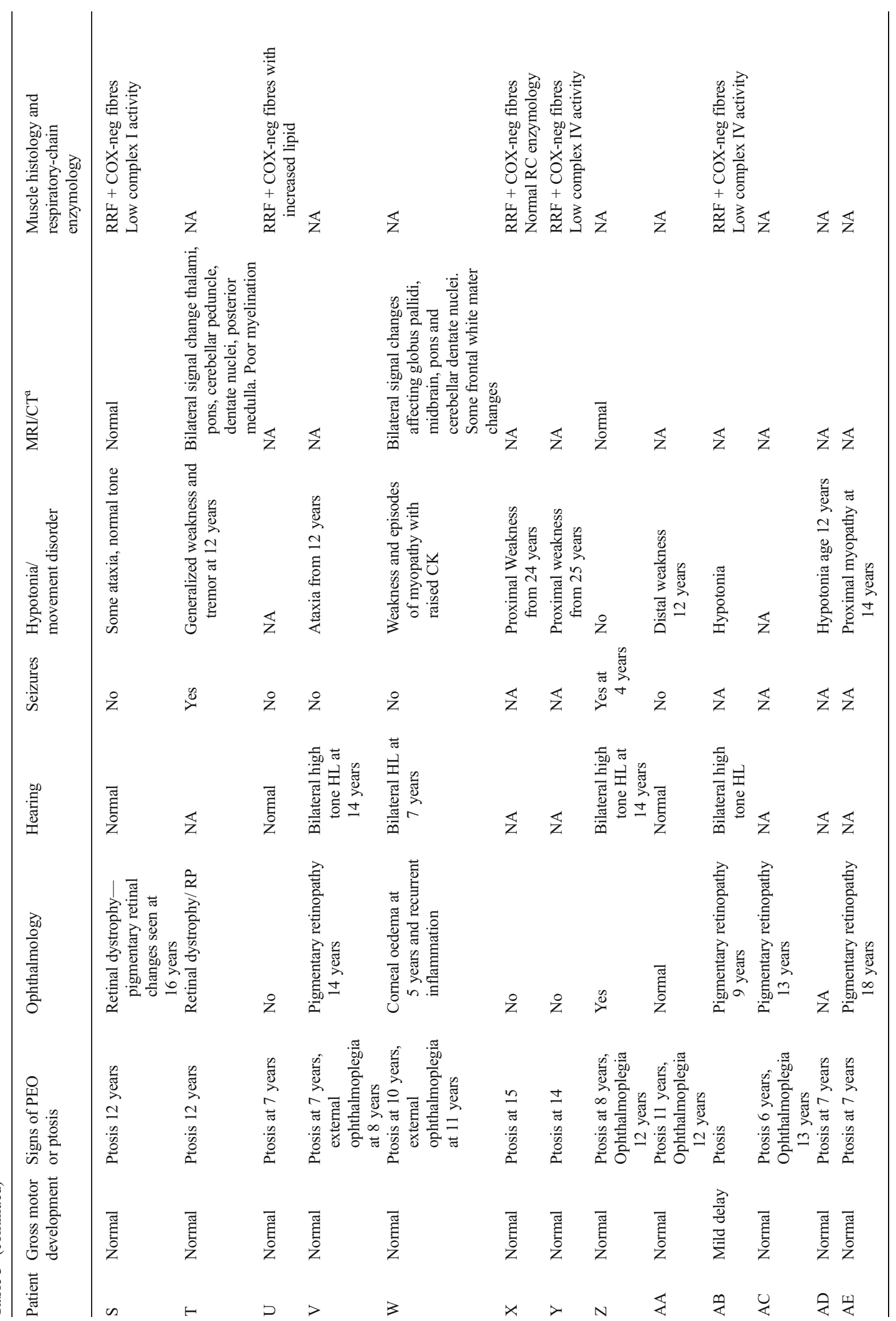


presentation ( $p=0.04, R^{2}=0.45$.) We observed no correlation between age at presentation and number of total RNA (tRNA) genes deleted or MT-CYB deletion in these 22 patients.

\section{Discussion}

While Kearns and Sayre's original clinical description was published in 1958 and Pearson's was published in 1979 (Kearns and Sayre 1958; Pearson et al. 1979), knowledge that mtDNA deletions were responsible was only established in 1988 (Holt et al. 1988). Subsequently, many individual case reports and case series have been published that increasingly suggest a clinical overlap between these historically different phenotypes (Manea et al. 2009; Yamashita et al. 2008; Pitceathly et al. 2012; Grady et al. 2014; McShane et al. 1991).

All 34 patients described here had single mtDNA deletions: 11 (A-J and AG) presented with varying degrees of anaemia and haematological dysfunction and fulfilled diagnostic criteria for the Pearson marrow-pancreas syndrome. However, pancreatic exocrine dysfunction was only documented in four: A, B, G and I (Table S2). Even in those with pancreatic dysfunction, the dysfunction was first documented at least 2 years after the initial presentation with anaemia, providing further evidence that the presence of pancreatic exocrine dysfunction should not be considered as an essential diagnostic criterion for Pearson syndrome. Our findings are in agreement with previous observations that one third of Pearson syndrome patients present solely with anaemia (Manea et al. 2009), with pancreatic dysfunction at presentation in only $12.7 \%$ of cases, although this increases to $18 \%$ by the age of 4 years (Lee et al. 2007). Low birth weight has previously been reported to be the most common nonhaematological finding in Pearson syndrome, affecting up to $63 \%$ of patients (Manea et al. 2009). While at first glance our cohort might appear to reinforce these observations, with four of ten being <3rd centile at birth, on closer examination, two of these patients (D and G) were born prematurely at 34 weeks' gestation, while patients $\mathrm{D}$ and $\mathrm{P}$ were second twins.

A novel finding of our study is the extent of multisystem disease in patients with Pearson syndrome (Fig. 3). Historically, $<20 \%$ of patients were reported to have symptoms unrelated to bone marrow or gastrointestinal tract (Manea et al. 2009), but in our cohort, all Pearson syndrome patients had involvement of other systems. The renal tract was most commonly involved, with evidence of renal dysfunction in five Pearson syndrome cases, including Fanconi-type tubulopathy in two cases $(\mathrm{G}$ and $\mathrm{H})$ and profound glomerular impairment in two (A and C). Renal involvement was not confined to those children with haematological problems, and 
Fig. 3 Number of different systems affected in each patient and impact on growth

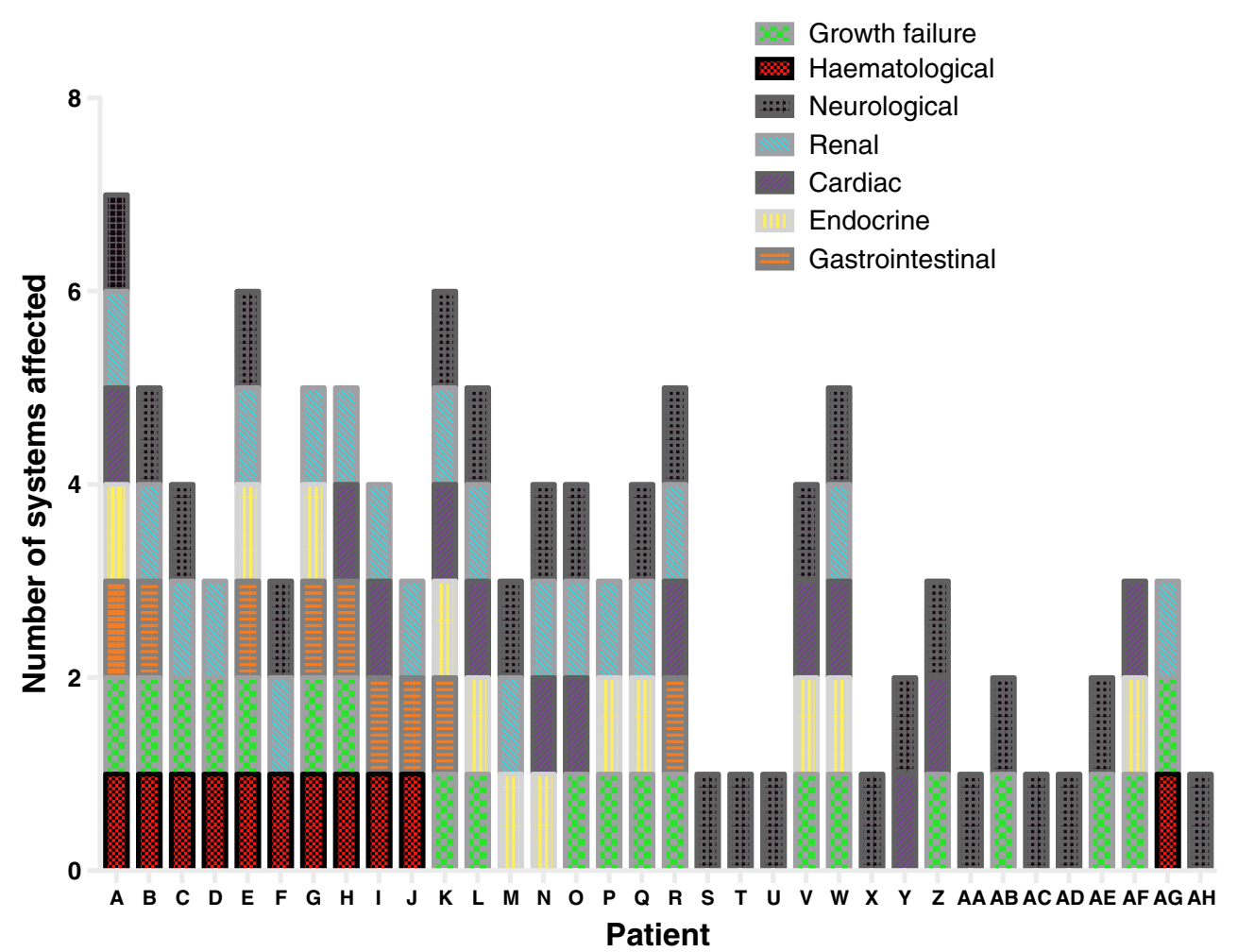

overall, 17 of $20(85 \%)$ patients for whom results were available had abnormal glomerular and/or tubular dysfunction. The majority of patients had proximal tubulopathy, but other renal manifestations included glomerular compromise (A, K, L and W), nephrocalcinosis (diagnosed on autopsy in $\mathrm{E}$ and by ultrasound in W). End-stage renal failure occurred in one patient $(\mathrm{K})$.

Our study demonstrates the relatively high frequency of renal disease in patients with mtDNA deletions. This is particularly interesting in light of previous observations of progressive renal failure in a murine model with mtDNA deletions (Inoue et al. 2000) and validates this model for preclinical trials of novel therapies for mtDNA deletion disorders. Furthermore, the utility of highly sensitive urinary markers of tubular damage, NAG and RBP (Herget-Rosenthal et al. 2004; Vaidya et al. 2008), allows presymptomatic detection of renal involvement and, consequently, early intervention. The presence of renal tubulopathy as detected by NAG/ creatinine and $\mathrm{RBP} /$ creatinine ratios can also be a useful diagnostic clue and serve to increase clinical suspicion of an underlying mitochondrial disorder.

Ten of the 23 patients whose presentation was not secondary to anaemia fulfilled clinical diagnostic criteria for KSS. Patients U, X and AD were classified as having PEO and patients $\mathrm{P}, \mathrm{Q}, \mathrm{Y}, \mathrm{AA}, \mathrm{AB}, \mathrm{AE}$ and $\mathrm{AH}$ as $\mathrm{PEO}+$, since ptosis is recognised to precede ophthalmoplegia by several years (Jackson et al. 1995). In 15 of the 16 patients with ptosis, it was the only clinical symptom at initial presentation. Since
SLSMDs can be detected noninvasively in children (on blood or urine analysis), we recommend that all children $>1$ year with undiagnosed new-onset ptosis should be screened for SLSMDs. It is to be noted, however, that ptosis in patient F was present at birth, and thus SLSMDs should be considered even in patients with apparent congenital ptosis, particularly if other systems subsequently become involved.

Cardiac involvement is well recognised in KSS and reported to affect almost $60 \%$ of cases (Berenberg et al. 1977). Cardiac manifestations are less well known in Pearson syndrome (Rahman and Leonard 2000; Krauch et al. 2002; Akaike et al. 1997), but we observed cardiac involvement in three of $11(27 \%)$ children: two had rhythm disturbances: patient I, and patient B previously reported by Rahman et al. (Rahman and Leonard 2000); one (H) had RVH. Cardiac manifestations in other phenotypic subgroups were two KSS and three $\mathrm{PEO}+$ patients (all had conduction defects), and three in the unclassified group ( $\mathrm{K}$ and $\mathrm{R}$ had LVH; L had atrial fibrillation).

The spectrum of neurological presentations in childhood SLSMDs is constantly increasing (Morel et al. 2009; Lee et al. 2007). In the study reported here, the major documented neurological findings were generalised hypotonia and muscle weakness, with resultant delay in gross motor development in five patients. Neuromuscular symptoms were more common in patients without haematological impairment, possibly reflecting the high mortality rate in patients with Pearson syndrome, i.e. patients died before onset of neuromuscular 
symptoms. Early mortality of Pearson patients likely also explains the predominance of brain imaging abnormalities in patients without bone marrow manifestations. The most frequently observed brain MRI abnormalities were basal ganglia and white matter lesions. A notable exception was patient $\mathrm{R}$, who appeared to show signs of impaired neuronal migration. To our knowledge, this is the first time an mtDNA deletion has been associated with imaging changes suggestive of a neuronal migration disorder, although other defects of mitochondrial oxidative phosphorylation (OXPHOS) function have been seen in patients with neuronal migration defects (van Straaten et al. 2005). As previously reported (McShane et al. 1991), we observed progression from Pearson syndrome to KSS in the two survivors who had long-term follow up.

Three patients, K, L and R, had no obvious external ophthalmoplegia or ptosis and, since they also did not have haematological compromise, fell outside any of the classical SLSMD phenotypes. They were diagnosed during investigation for other problems: faltering growth (K), Fanconi syndrome (L) and persistent neonatal lactic acidosis (R). Since patients with multisystem involvement are increasingly being investigated for mitochondrial disorders, it is likely that in the future a greater number of children will fall into this illdefined group and new phenotypes of SLSMDs will emerge.

The range of clinical phenotypes was reflected in the varied need for symptomatic support. The need for careful endocrinology monitoring is evidenced by the requirement for hormone replacement in 12 of our cases: one required thyroxine, four cortisol replacement therapy, three vitamin D for hypoparathyroidism and three growth hormone. However, as might be expected, the most common endocrine abnormality was diabetes mellitus; five of the nine patients with abnormal glucose tolerance tests required insulin. Patients with impaired pancreatic exocrine function required pancreatic enzyme replacement. The other commonly compromised systems were cardiac (pacing was required in five patients) and renal: eight patients needed medical therapy (electrolyte replacement, in very high doses in some cases), one had renal replacement therapy while being considered for a transplant and one had lithotripsy to treat renal calculi. Finally, the importance of regular audiometry is emphasised by the finding of impaired hearing in ten patients and the need for cochlear implantation in one. This degree of multidisciplinary input, with contribution to management by specialist audiological physicians, cardiologists, endocrinologists, gastroenterologists, haematologists, nephrologists, neurologists, ophthalmologists and palliative care physicians, again emphasises the need for coordinated care of children with SLSMDs at a tertiary specialist centre.

Overall, our data provides further support for a clinical continuum of syndromes associated with SLSMDs manifesting in childhood. However, subdivision into Pearson syndrome and KSS may be useful for prognosis, as demonstrated by survival analysis of this cohort (Fig. 2). Five-year survival in patients manifesting with a Pearson phenotype was $<50 \%$ from time of initial presentation compared with $100 \%$ for other phenotypic subgroups $(P<0.001)$. Although this mortality rate is high, it is considerably lower than a historical report of $76 \%$ 5-year mortality (Rotig et al. 1995). Interestingly, survival at 4 years was $55 \%$ in a more recent cohort (Manea et al. 2009), suggesting the possibility that earlier recognition of Pearson syndrome and intense management of known complications may be improving survival rates. Furthermore, all patients with Pearson syndrome who survived to 8 years were still alive at 18 years, which may be a useful prognostic feature when counselling parents and important information in planning transition to adult services.

Genotype-phenotype correlation for SLSMDs remains controversial. Traditionally, there was thought to be no relationship between the length of mtDNA deletion and clinical phenotype (Lopez-Gallardo et al. 2009; Rotig et al. 1995; Aure et al. 2007). However more recent work suggests that location (Lopez-Gallardo et al. 2009; Yamashita et al. 2008) and number of deleted tRNA molecules (Yamashita et al. 2008) may possibly influence phenotype, and a study of 87 patients (only five of whom presented younger than 20 years) indicated that mtDNA deletion size was correlated with both age at onset and progression rate. However, the impact of deletion size was mediated by the degree of heteroplasmy seen in muscle biopsy (Grady et al. 2014). It also suggested that deletion of the MT-CYB gene was associated with a more severe phenotype. In contrast, in our cohort, we found no correlation between patient age and deletion size or MT-CYB deletion. There was a significant, if minor, statistical correlation between degree of heteroplasmy and age at presentation. However, since quantitation was performed using visual inspection, this finding should be interpreted with caution.

\section{Conclusions}

This retrospective cohort of patients with childhood-onset SLSMDs provides further evidence for a continuous clinical spectrum of disease associated with this genetic defect, including the occurrence of atypical presentations. Clinicians (including general paediatricians, neonatologists, ophthalmologists, renal physicians, endocrinologists, gastroenterologists, haematologists, child neurologists and paediatric metabolic specialists) should be aware of these heterogeneous presentations and maintain a high degree of suspicion for SLSMDs. Clinical features that should particularly raise suspicion of SLSMDs in children include sideroblastic anaemia, ptosis and multisystem disease with neurological, cardiac, renal and/or gastrointestinal manifestations. We find no correlation between deletion size and location and phenotype, but clinical categorisation into Pearson syndrome, KSS or PEO continues 
to be an important tool for prognostication. Longer survival of Pearson syndrome patients in this cohort compared with historical cohorts emphasises the importance of proactively monitoring for and aggressively managing known multisystem complications, including cardiac conduction defects, diabetes mellitus and renal impairment.

Acknowledgments SR and PTC are supported by the Great Ormond Street Hospital Children's Charity. The authors thank the audiological physicians, biochemists, cardiologists, endocrinologists, gastroenterologists, haematologists, nephrologists, neurologists, ophthalmologists, palliative care physicians and pathologists involved in the diagnosis and management of these patients. MtDNA breakage points of patient $\mathrm{E}$ were determined in the NSCT mitochondrial laboratory, Newcastle.

\section{Conflict of interest None.}

Open Access This article is distributed under the terms of the Creative Commons Attribution License which permits any use, distribution, and reproduction in any medium, provided the original author(s) and the source are credited.

\section{References}

Akaike M, Kawai H, Yokoi K et al (1997) Cardiac dysfunction in patients with chronic progressive external ophthalmoplegia. Clin Cardiol 20: 239-243

Aure K, Ogier de Baulny H, Laforet P et al (2007) Chronic progressive ophthalmoplegia with large-scale mtDNA rearrangement: can we predict progression? Brain 130:1516-1524

Berenberg RA, Pellock JM, DiMauro S et al (1977) Lumping or splitting? "Ophthalmoplegia-plus" or Kearns-Sayre syndrome? Ann Neurol 1: $37-54$

Bernard AM, Vyskocil AA, Mahieu P, Lauwerys RR (1987) Assessment of urinary retinol-binding protein as an index of proximal tubular injury. Clin Chem 33:775-779

Biousse V, Newman NJ (2001) Neuro-ophthalmology of mitochondrial diseases. Semin Neurol 21:275-291

Di Mauro S, Hirano M (1993-2014) Mitochondrial DNA deletion syndromes. In: Pagon RA, Adam MP, ardinger HH et al (eds) Genereview ${ }^{\mathcal{O}}$ [Internet]. Seattle(WA):University of Washington, Seattle Dimauro S (2007) Mitochondrial DNA, medicine. Biosci Rep 27:5-9

Drachman DA (1968) Ophthalmoplegia plus. The neurodegenerative disorders associated with progressive external ophthalmoplegia. Arch Neurol 18:654-674

Grady JP, Campbell G, Ratnaike T et al (2014) Disease progression in patients with single, large-scale mitochondrial DNA deletions. Brain 137:232-34

Herget-Rosenthal S, Poppen D, Husing J et al (2004) Prognostic value of tubular proteinuria and enzymuria in nonoliguric acute tubular necrosis. Clin Chem 50:552-558

Holt IJ, Harding AE, Morgan-Hughes JA (1988) Deletions of muscle mitochondrial DNA in patients with mitochondrial myopathies. Nature 331:717-719

Holt IJ, Harding AE, Cooper JM et al (1989) Mitochondrial myopathies: clinical and biochemical features of 30 patients with major deletions of muscle mitochondrial DNA. Ann Neurol 26:699-708

Inoue K, Nakada K, Ogura A et al (2000) Generation of mice with mitochondrial dysfunction by introducing mouse mtDNA carrying a deletion into zygotes. Nat Genet 26:176-181
Jackson MJ, Schaefer JA, Johnson MA, Morris AA, Turnbull DM, Bindoff LA (1995) Presentation and clinical investigation of mitochondrial respiratory chain disease. A study of 51 patients. Brain 118(Pt 2):339-357

Kearns TP, Sayre GP (1958) Retinitis pigmentosa, external ophthalmophegia, and complete heart block: unusual syndrome with histologic study in one of two cases. AMA Arch Ophthalmol 60: 280-289

Krauch G, Wilichowski E, Schmidt KG, Mayatepek E (2002) Pearson marrow-pancreas syndrome with worsening cardiac function caused by pleiotropic rearrangement of mitochondrial DNA. Am J Med Genet 110:57-61

Krishnan KJ, Reeve AK, Samuels DC et al (2008) What causes mitochondrial DNA deletions in human cells? Nat Genet 40: 275-279

Lamont PJ, Surtees R, Woodward CE, Leonard JV, Wood NW, Harding AE (1998) Clinical and laboratory findings in referrals for mitochondrial DNA analysis. Arch Dis Child 79:22-27

Lee HF, Lee HJ, Chi CS, Tsai CR, Chang TK, Wang CJ (2007) The neurological evolution of Pearson syndrome: case report and literature review. Eur J Paediatr Neurol 11:208-214

Lopez-Gallardo E, Lopez-Perez MJ, Montoya J, Ruiz-Pesini E (2009) CPEO and KSS differ in the percentage and location of the mtDNA deletion. Mitochondrion 9:314-317

Manea EM, Leverger G, Bellmann F et al (2009) Pearson syndrome in the neonatal period: two case reports and review of the literature. $\mathrm{J}$ Pediatr Hematol Oncol 31:947-951

McShane MA, Hammans SR, Sweeney M et al (1991) Pearson syndrome and mitochondrial encephalomyopathy in a patient with a deletion of mtDNA. Am J Hum Genet 48:39-42

Morel AS, Joris N, Meuli R et al (2009) Early neurological impairment and severe anemia in a newborn with Pearson syndrome. Eur J Pediatr 168:311-315

Morris AA, Lamont PJ, Clayton PT (1997) Pearson's syndrome without marrow involvement. Arch Dis Child 77:56-57

Pearson HA, Lobel JS, Kocoshis SA et al (1979) A new syndrome of refractory sideroblastic anemia with vacuolization of marrow precursors and exocrine pancreatic dysfunction. J Pediatr 95: 976-984

Pitceathly RD, Rahman S, Hanna MG (2012) Single deletions in mitochondrial DNA-molecular mechanisms and disease phenotypes in clinical practice. Neuromuscul Disord 22:577-586

Poulton J, Deadman ME, Gardiner RM (1989) Duplications of mitochondrial DNA in mitochondrial myopathy. Lancet 1 : 236-240

Poulton J, Deadman ME, Bindoff L, Morten K, Land J, Brown G (1993) Families of mtDNA re-arrangements can be detected in patients with mtDNA deletions: duplications may be a transient intermediate form. Hum Mol Genet 2:23-30

Rahman S, Leonard JV (2000) Early onset of complete heart block in Pearson syndrome. J Inherit Metab Dis 23:753-754

Riera AR, Kaiser E, Levine P et al (2008) Kearns-Sayre syndrome: electro-vectorcardiographic evolution for left septal fascicular block of the his bundle. J Electrocardiol 41:675-678

Rotig A, Bourgeron T, Chretien D, Rustin P, Munnich A (1995) Spectrum of mitochondrial DNA rearrangements in the Pearson marrow-pancreas syndrome. Hum Mol Genet 4: $1327-1330$

Rowland LP (1983) Molecular genetics, pseudogenetics, and clinical neurology. The Robert Wartenberg lecture. Neurology 33: $1179-1195$

Schaefer AM, Taylor RW, Turnbull DM, Chinnery PF (2004) The epidemiology of mitochondrial disorders-past, present and future. Biochim Biophys Acta 1659:115-120

Shoffner JM, Lott MT, Voljavec AS, Soueidan SA, Costigan DA, Wallace DC (1989) Spontaneous Kearns-Sayre/chronic external 
ophthalmoplegia plus syndrome associated with a mitochondrial DNA deletion: a slip-replication model and metabolic therapy. Proc Natl Acad Sci U S A 86:7952-7956

Skladal D, Halliday J, Thorburn DR (2003) Minimum birth prevalence of mitochondrial respiratory chain disorders in children. Brain 126: 1905-1912 van Straaten HL, van Tintelen JP, Trijbels JM et al (2005) Neonatal lactic acidosis, complex I/IV deficiency, and fetal cerebral disruption. Neuropediatrics 36:193-199

Yamashita S, Nishino I, Nonaka I, Goto Y (2008) Genotype and phenotype analyses in 136 patients with single large-scale mitochondrial DNA deletions. J Hum Genet 53:598-606 